\title{
Understanding Women's Gendered Experiences in Physics and Astronomy Through Microaggressions
}

\author{
Ramón S. Barthelemy*, Melinda McCormick† and Charles Henderson \\ *Department of Physics, University of Michigan, 500 S. State Street, Ann Arbor MI, 48109 \\ $\dagger$ Department of Sociology, Western Michigan University, 1903 W. Michigan Avenue, Kalamazoo, MI 49008 \\ "Department of Physics and Mallinson Institute for Science Education, Western Michigan University, 1903 W. \\ Michigan Avenue, Kalamazoo, MI 49008
}

\begin{abstract}
The issue of women's representation and success in physics has been an important area of investigation in the physics education research community. Much of the research attempting to explore this area has focused on educational gender differences in the classroom, references to chilly climates, and work-life balance. Almost no research has specifically talked about issues of gender discrimination. This article begins such an area of research by focusing on the gender discrimination experienced by women in graduate physics and astronomy programs through the lens of microaggressions; which are subtle daily acts of discrimination. Findings indicate that women are often unconsciously ignored by male colleagues, suffer from conscious discriminatory comments, and find themselves ignored when seeking resolution to these issues. Their experiences can be understood and organized in the three main microaggression constructs: microinsults, microaggressions, and microinvalidations. This organization helps to develop a language to discuss these issues in physics and facilitate future research in the field.
\end{abstract}

Keywords: Women in Physics, gender, discrimination, microaggressions

PACS: $01.40 . \mathrm{FK}$

\section{INTRODUCTION}

The low representation of women in physics has been a significant concern in the Physics Education Research (PER) literature [1, 2]. This work has largely addressed issues in the classroom [1] or workplace choices [2]. These articles have been an important foundation in describing, understanding, and improving women's experiences in physics.

Undergraduate gender research has often focused on learning differences in the classroom with respect to conceptual gains and exam scores amongst others [1]. Graduate education research has recently focused on women's desires to have a family, life outside of research, and career [2]. Women in graduate physics have described their life goals as being incompatible with a career in academic research.

Other work focused on women in science at large has looked at their persistence in the often mentioned pipeline model, and the chilly experiences they may have as graduate students and faculty [3]. These chilly experiences are often due to hostile work environments and their exclusion in research. This work, however, did not specifically focus on issues of gender discrimination, which may be an important area of concern in PER.

Research in PER has not yet addressed the topic of gender or sex discrimination in physics, which may be impacting the success of students. Multiple studies in the sciences at large have demonstrated how women are often viewed and treated differently than men [4, 5], but none have focused specifically on physics.

In order to begin this conversation, this article examines the gendered experiences of women in physics through the lens of microaggressions. Microaggressions are subtle displays of discrimination, often unconscious, that accumulate over time to have negative impacts on marginalized persons' (i.e. women's) careers and well-being [6].

Early efforts in this area primarily focused on race, but research has since studied the issues faced by women. These may include exclusion of (or ignoring) women, questioning their abilities, making sexist jokes, and more [6]. Microaggressions occur on an everyday basis and pervade social interactions. They can be transmitted verbally, behaviorally or environmentally. The focus of this work will be on those aggressions delivered verbally to women.

Many other kinds of sexism and gender discrimination exist beyond microaggressions, but this article will only focus on the latter. Within the frame of microaggressions, graduate women's experiences in physics and astronomy will be organized within three constructs to be discussed further: microinsults, microassaults, and microinvalidations [6]. 
These three categories are the canonical organization of the types of microaggressions. Within each type, though, there is a great diversity in how the experiences can manifest. Due to this nature of microaggressions the bulk of the literature exploring the topic has been qualitative. Implications for what to do with the findings have suggested that discussions of race, gender, sexual orientation, and other marginalized groups needs to be facilitated in the classroom and workplace [7]. If people are not made aware of their subtle negative social interactions then it is not possible for them to reflect on their actions and interact with others more hospitably and less offensively.

\section{METHODS}

The data used in this article stems from a larger project looking at the graduate experiences of women in physics and astronomy. Women in graduate physics and astronomy programs at four well-ranked research universities $(\mathrm{N}=21)$ were interviewed using openended prompts about their collegiate experiences [8]. Consequently, the results are delimited to women's experiences at large research universities. These women were randomly sampled for study inclusion from all women at these institutions. Participants had passed their qualifying exams and were at an advanced stage of their training. Further details about the participants will not be provided to help ensure anonymity. For this analysis responses to the following prompt will be analyzed: 'Do you feel that your experience in physics (astronomy) has been different because you are a woman?'

All interviews were conducted face-to-face, transcribed, and sent back to participants to read over for accuracy and clarity. They were also allowed to omit sensitive information about themselves that might reveal their identities and raise any other concerns.

Interviews were coded using a two-tiered system of action codes that looked for concrete experiences and themes that brought together these experiences to form meaning. Both the first and second author coded all the data to ensure reliability and validity [8]. Each author brought their own perspective into the process, such as being a male in physics education, and female in sociology. Interviews were first read for action codes, that were then grouped together based on similarities. These similarities evolved into themes of participant experiences that were discussed amongst the authors.

The results section will unfold in three parts. Part 1 will look at microinsults experienced by the women, which are subtle communications that ignore or exclude women. Part 2 will look at microassaults, which are conscious character assaults on women that include sexist comments and jokes. Lastly, Part 3 will look at microinvalidations, which are communications that negate women's lived experiences with respect to their gender.

\section{RESULTS}

Of the twenty-one participants, five reported having no gendered experiences, one reported benefiting from women in astronomy programs, and fifteen reported having had negative gendered experiences. The results will be organized below by microaggression type and will offer summaries with salient examples. Most of these experiences occurred at the graduate level, but a few reported events happened at the undergraduate level, and one while the participant was in high school.

\section{Microinsults}

Microinsults are often unconscious and communicate to a woman that she is not competent, her ideas are not valid, or that she does not belong, amongst other negative messages [6]. The interpretation of an event as a microinsult is personal. Although the reader may see an event below as not being an insult, the women who are quoted experienced them as such. To this end, their experience will be considered valid and a microinsult. The women who reported suffering from what could be categorized as microinsults were largely being ignored, were being overlooked, or were not having their voices heard within the context of their research and group meetings. These sorts of interactions occurred both with other students and with faculty members.

One participant in physics explained her interaction with a graduate student:

I told the grad student under me that he should consider a certain factor in trying to make sense of his data. He said no and ignored me. When the other grad student/post doc [male] suggested it, he was open to it right away.

As an undergraduate student, a participant in astronomy found herself often ignored during her allmale research group meeting. She saw these microinsults as being unconscious and something the men were not even aware of performing:

...I know they're not consciously sexist in any way. But there were times where, like, we'd be like in a group there'd be like one male professor, two students [male], and me, and no one would be making eye contact with me. And sometimes I would make a statement and no one would hear it. It was like I wasn't in the conversation. It was really really frustrating. I would leave 
sometimes...really upset. And I felt...not respected and it wasn't 'till... after the end of that summer that I looked back and I was like, what was wrong there?

For another physics student, her experience of microinsults came in the form of other researchers assuming she was not competent with tools used in research:

I think most people interact with you a little differently when you are a woman, whether they mean to or not -- they just make different assumptions about your abilities and interests, and how to interact with you in general. Has anyone ever asked you if you know how to use a wrench? [asked to male interviewer]

Similar to the student above, another physics student felt she was often questioned about her research interests because of her gender:

When talking to faculty, both male and female in particle theory...my interest in particle theory is questioned in one form or another. Examples include "you know that it's very difficult, right?" "Have you considered particle experiment?" "Are you sure that you want to do particle theory?" "Are you still sure that you want to do particle theory?" "Have you considered alternatives?"

These slights were frequent, subtle, and potentially unconscious. However, their impact was significant in that they silenced the women students' ability to participate fully in their research and graduate experiences. Another class of microaggressions, however, is not as subtle and is often conscious; these are known as microassaults.

\section{Microassaults}

Microassaults differ from microinsults in that they are purposeful, are targeted towards women, and are frequently a very conscious action. For the women in this study, these came in the form of offensive jokes, lewd comments, references to the inferiority of women, and restrictions from laboratory equipment.

Particiants in both physics and astronomy experienced direct verbal assaults during their attempts to conduct research. The theme was the same-- women should be at home and not in the lab:

Physics student: He's not too fond of women, in general. And he made a point to make sure I understood that ... He thought that women should be homemakers...that's how he thought all women should be. And so, he just wouldn't talk to me... if I asked for something, like, I want time to do experiment stuff.... He wouldn't give it to me.

Astronomy student: ...[a male graduate student was] just going on about why women can't do science because they should be taking care of babies and I should be thinking about having babies soon because once I get older it gets harder. It was absolutely crazy and so frustrating, like, I literally, like, couldn't even deal with this person...I just feel so disrespected...

Another participant experienced a microassault as a high school student. When she said she wanted to be physics major, her teacher responded sarcastically:

...the teacher was asking everyone in the class...where we would be going to college and what we wanted to study...Many of the boys in the class expressed interest in engineering. When it got around to me, I responded that I wanted to major in physics. The teacher raised an eyebrow and said "Oh, so you're going to be a waitress."

Microassaults are painful and purposeful. They may act to discourage women and create an internal feeling that they may not belong in physics. The last category of microaggressions, though, is often unconscious and functions as a way of ignoring the gendered lives of women rather than verbally harassing them. These are known as microinvalidations.

\section{Microinvalidations}

Microinvalidations assess women's gendered experiences as being non-existent or something the woman is only imagining [6]. For the women in this study, microinvalidations often occurred when they reported issues of gender discrimination. Of the four participants who reported microassaults against them, only one was met with an advisor response that resolved the issue. The other three were met with silence, or with an explanation to the student that nothing was really occurring:

...it was a problem [jokes about rape in the lab], I talked to my advisor about it...nothing was ever done about it...

In one case, a participant was being restricted from laboratory equipment needed to do her research because a male colleague did not like working with women. She talked to her advisor about the issue, but found no support: 
...my advisor was leaning towards taking more his side in any conflicts. And, so, you know, that made me even more frustrated ...

Eventually this participant quit her research group and found a new advisor who had a strong track record of supporting women in physics.

This sort of inaction and assumption of no wrongdoing on the behalf of male scientists endangers women's participation in their graduate programs. They may eventually feel helpless to respond to gender discrimination and may stop reporting harassment, as it often goes unanswered:

I complained to the chair of the department about a male faculty member for several reasons, including my worry that perhaps the man was sexist (I ended the complaint with the statement that I hoped to be incorrect about this). I never received any reply whatsoever.

In the case of one participant, she left the country after her department refused to discipline a fellow graduate student who became increasingly sexually aggressive. This aggression, though, soon moved beyond the micro realm into full aggressionpresenting a potent reminder of what some women may face in the physics and astronomy communities:

He was obsessive, violent towards objects. I just wanted to get away from him...he punched holes in the wall because I happened to be in the building...He was angry at me... he didn't respond to 'leave me alone.'

Without immediate investigations and appropriate responses, unchecked microaggressions will give the signal that it is acceptable for males to be perpetrators, and women have little to no recourse to appropriate intervention. Letting such an environment thrive is counter-productive to student development and may affect female students' decisions as they begin choosing careers. Ensuring a safe and collegial work environment is an important component of supporting all students, particularly women.

\section{CONCLUSION}

The results from this study indicate that women may face particular microaggressions in pursuit of their graduate educations. Their experiences range from being ignored to being restricted from laboratory equipment and suffering from peer sexual aggression. Unfortunately, those who report their experiences of microassaults were often ignored and left to survive for themselves.
These findings fit within the current literature on microaggressions and suggest that the microaggressions literature may help to build and fuel future research in PER, while also giving the field a language to use in understanding gender discrimination in physics. Future work should continue to explore women's experiences at all phases of a physics career.

An interesting area of future research might look at the microaggressions experienced by women in undergraduate physics. Such research could unfold in a mixed methods approach and test for the impact of microaggressions on student persistence. It would also be possible to develop guidelines for departments to consider to reduce microaggressions in their physics programs.

By uncovering women's current conditions, it will help to better inform policy and interventions. The implementation of these findings may help to increase women's success and facilitate a more productive physics learning environment for all persons.

\section{ACKNOWLEDGMENTS}

The authors would like to thank the Michigan Space Grant for funding this work and all the women who participated in the study.

\section{REFERENCES}

1. L. Kost-Smith, S. Pollock, and N. Finkelstein, "Gender disparities in second-semester college physics: The incremental effects of a "smog of bias."," Physical Review Spcal Topics- Physics Education Research 6, 201 (2010).

2. K. P. Dabney, and R. H. Tai, "Female physicist doctoral experiences," Physical Review Spcal Topics- Physics Education Research 9, (2013).

3. C. J. Blickenstaff, "Women and science careers: Leaky pipeline or gender filter?," Gender and Education 17, 369 (2005).

4. C. Wenneras, and A. Wold, "Nepotism and sexism in peer-review," Nature 387, 341 (1997).

5. C. A. Moss-Racusin et al., " Science faculty's subtle gender biases favor male students," Proceedings of the National Academy of Sciences of the United States of America 109, 16474 (2012).

6. D. W. Sue, Microaggressions and marginality: Manifestation, dynamics, and impact (John Wiley \& Sons, Inc., Hoboken, NJ, 2010).

7. D. W. Sue et al., "Racial microaggressions in everyday life: Implications for clinical practice," American Psychologist 62, 271 (2007).

8. J. W. Creswell, Qualitative inquiry \& research design: Choosing among five approaches (Sage Publications, Thousand Oaks, CA, 2007). 